\title{
Ervilhas congeladas - 0 prossumidor contemporâneo e a exuberância cosmética dos produtos
}

\section{João Anzanello Carrascoza}

Doutor; Escola Superior de Propaganda e Marketing, São Paulo,SP, Brasil

jcarrascoza@espm.br

\section{Resumo}

Com a consolidação da cultura de consumo nas últimas décadas, novos agentes da relação entre produção e consumo surgiram, entre os quais o prossumidor - consumidor que é também produtor, uma vez que participa, voluntariamente ou não, do processo produtivo dos bens. Pretendemos, neste artigo, discutir aspectos ligados à "contribuição" do prossumidor no desenvolvimento de produtos, bem como em boicotes virtuais a seus fabricantes, por meio do conto Carta a um fabricante de ervilhas congeladas, da escritora Lydia Davis (2017). Para isso, mobilizaremos conceitos da teoria literária, do processo criativo publicitário e dos estudos sobre sociedade e consumo.

\section{Palavras-chave}

Prossumidor. Comunicação. Publicidade. Embalagem. Literatura.

\section{Mercadoria: do fetiche do consumo ao artifício da produção}

A esfera de produção de mercadorias pressupõe, como condição inerente à sua existência, a esfera consequente do consumo, pela qual o que foi produzido encontra o sujeito que o consome - e o consuma. Essa segunda esfera, por sua vez, só tem razão de ser por preceder a outra, que para ela produz, gerando ambas um circuito não apenas de justaposição, mas de aglutinação. Assim, não existe uma produção, seja do que for, de per si toda e qualquer produção é guiada pela esfera que lhe sucede, e vice-versa, incluindo a economia discursiva, uma vez que é imensa, na comunicação midiática, a quantidade de discursos produzidos e, igualmente, consumidos.

Marx (1992) explicou essa dinâmica, afirmando que "[...] ao dissolver o produto, o consumo lhe dá seu retoque final, pois o produto não é apenas a produção enquanto 
atividade coisificada, mas [também] enquanto objeto para o sujeito em atividade." (MARX, 1992, p. 8).

Apoiando a sua investigação sobre a magia e o capitalismo no paradigma marxista, Everardo Rocha (1990) nos mostra que, no domínio da produção, há uma espécie de desumanização, enquanto no domínio do consumo, o ser humano é divinizado, cabendo à publicidade essa operação transformadora - e, para nós, também performativa -, que Rocha (1990), valendo-se dos estudos de Lévi-Strauss, diz se assemelhar à dos totens nas civilizações primitivas. A publicidade, então, operando de forma similar à da "magia", oculta do percurso das mercadorias o universo de exploração do homem pelo homem no âmbito da produção e pontua com máxima luz o universo glamouroso do consumo, no qual o ser humano é tratado, então, como rei. Em outras palavras,

[...] o discurso da publicidade é o de omitir sistematicamente os processos objetivos de produção e a história social do produto. Através dela o produto encontra o homem numa instância lúdica de um imaginário gratificante (ROCHA, 1990, p. 66).

A instância do consumo transforma o produto, pois, em fábulas e imagens.

Essa metamorfose se processa e se realiza por meio do sistema publicitário, constituído não apenas pelas campanhas de publicidade dos produtos, mas por toda a construção discursiva que o sustém, como seu nome de batismo, seu design, sua marca e demais elementos que lhes conferem existência material e simbólica. Torres I Prat (2005) nomeia essa maquinaria de CC-P (complexo comercial-publicitário), comparando-o à Matrix, em referência ao filme dirigido pelas irmãs Wachowski, como metáfora de um "construto social e tecnológico que tem vida própria" (TORRES I PRAT, 2005, p. 13).

Nesse contexto, a embalagem dos produtos é um aspecto expressivo e determinante de sua aparência, um fator que consubstancia sua estética e, inicia, junto com seu nome, a sua discursividade publicitária. Em sua clássica crítica da economia política, Marx (2011) apontou o fetiche que a mercadoria exerce (como se ela ganhasse vida própria) - e, evidentemente, a maneira como é ela "embalada" afasta ou aproxima o consumidor.

Nosso objetivo é problematizar e discutir a participação ativa e ativista do consumidor na criação e no aprimoramento de mercadorias a partir do conto Carta a um fabricante de ervilhas congeladas", da escritora norte-americana Lydia Davis (2017), dando sequência a nossos estudos sobre consumo tendo como metodologia a retextualização (BETTETINI, 1996) - mais precisamente o uso de textos literários na reflexão científica. 
Davis (2017) é uma prosadora singular, suas narrativas se revelam configurações híbridas que se distanciam e se acercam ao mesmo tempo do conto, da poesia, do relato memorialístico, e, na falta de designação mais precisa, são chamadas de ficções. A autora pertence a uma linhagem de escritores norte-americanos que se notabilizaram produzindo contos longos, como John Cheever, Raymond Carver e Lucia Berlin (a quem Lydia Davis atribuía uma escrita empolgante), embora um de seus traços estilísticos seja também - e aí reside uma diferenciação em relação aos contistas citados - a criação de histórias curtíssimas, resvalando, e tantas vezes assumindo, o formato de minicontos, e até mesmo o de micronarrativas.

O conto em questão, publicado em seu livro Nem vem, é uma carta, como diz o título, na qual a narradora envia ao fabricante de uma marca de ervilhas congeladas uma crítica à coloração do produto em sua embalagem, como vamos ver a seguir no desdobrar de nossa abordagem. Nessa obra, há outros contos em forma de missiva - Carta a um gerente de marketing, Carta a uma fábrica de balas de menta e Carta à Fundação - igualmente narrados por um consumidor que tem algo a testemunhar e a questionar sobre um produto (ou serviço), ou a sugerir como mudança, que nos servirão, numa outra oportunidade, para investigar como uma rede de arrasto aspectos da relação produção/consumo contemplados na carta ao fabricante de ervilhas.

\section{Críticas e sugestões estéticas}

Sem preâmbulos, já nas primeiras linhas da Carta a um fabricante de ervilhas congeladas, o narrador-remetente expõe a razão principal de a ter escrito e encaminhado à empresa produtora, à semelhança das cartas enviadas pelo público consumidor ao departamento de marketing e de publicidade de fábricas em geral - exemplo de fácil visualidade como as cartas dos leitores na imprensa diária, publicadas resumidamente pelos jornais (uma nítida estratégia editorial). Esse tipo de carta pode trazer elogios e sugestões, mas, em geral, carrega críticas sobre o produto, motivação que o texto de Lydia Davis (2017) reproduz como uma mimese desse gênero de correspondência-padrão:

Decidimos lhe escrever porque achamos que as ervilhas na ilustração de sua embalagem de ervilhas congeladas apresentam uma coloração extremamente ingrata. Referimo-nos à embalagem plástica de quinhentos gramas com uma imagem de três ou quatro vagens, uma delas aberta, com algumas ervilhas em torno. As ervilhas são de um verde-amarelado fosco, mais cor de sopa de ervilhas que de ervilhas frescas, e bem diferente da cor 
real de suas ervilhas, que são de um verde-escuro vivo e intenso. (DAVIS, 2017, p. 45).

A carta aponta, de saída, o descompasso entre a qualidade do produto, atestada pelo remetente consumidor - as ervilhas são de cor verde-escuro vivo e intenso - e a cor das ervilhas de embalagem de quinhentos gramas é verde-amarelado fosco, que não coincide com a cor de suas ervilhas frescas. A constatação nos leva a refletir sobre a estética das mercadorias, tanto na sua materialidade propriamente dita quanto na embalagem que a protege e a considerá-la, em simultâneo, como um dos vetores enunciativos de seu discurso.

Se o nome do produto é a gênese da história discursiva de um produto, a embalagem é estampa que o apresenta no mercado, revelando aos olhos do público a sua personalidade nas prateleiras dos signos, sendo, assim, um elemento determinante de diferenciação e, sobretudo, de distinção. A embalagem artisticamente esmerada alarga o valor de troca da mercadoria, de forma que há, por meio do sistema publicitário, um investimento considerável na criação da embalagem de qualquer produto. Em rigor, há uma cosmética da exuberância em ação para dar às mercadorias uma aparência para além de sua realidade material.

O segmento gastronômico é um dos mais competentes na criação de embalagens, uma vez que a imagem dos alimentos (em especial os perecíveis) exige retoques em seu registro fotográfico, a fim de lhes garantir appetite appeal. Esse apelo visa a despertar o apetite do consumidor, mas se concretiza numa imagem maquiada da comida. Vale salientar que, se o apelo é ou não efetivo, a imagem do alimento já constitui um tipo de consumo simbólico, imagético, midiático -, daí porque Rocha (1990) nos lembra que

[...] se compararmos o fenômeno do "consumo" de anúncios e o de produtos, iremos perceber que o volume de "consumo" implicado no primeiro é infinitamente superior ao do segundo. 0 "consumo" de anúncios não se confunde com o "consumo" de produtos. Podemos até pensar que o que menos se consume num anúncio é o produto. (ROCHA, 1990, p. 27).

É possível afirmarmos o mesmo em relação ao consumo de embalagens e o de produtos: o primeiro é discursivo, antecede o consumo de produtos e pode ou não levar a ele - à compra ou à experimentação dos bens embalados.

A queixa do missivista ao fabricante de ervilhas congeladas se direciona, portanto, à falta de appetite appeal da embalagem, que, podemos afiançar, não teria passado pela cosmética da exuberância para assegurar à imagem das ervilhas o frescor (a cor verde vivo) que elas teriam, deixando-as visualmente com uma cor mais próxima à de uma sopa de 
ervilhas (verde fosco), ou seja, para além do ponto desejável ao consumo. A crítica à empresa se amplia, pois o remetente da carta ressalta ainda que

[...] as ervilhas retratadas são três vezes maiores do que as que se encontram dentro do pacote, o que, juntamente com a coloração fosca, torna o conjunto ainda menos apetecível - passa a impressão de que as ervilhas estão maduras demais. (DAVIS, 2017, p. 45).

Ele acrescenta outra dissonância entre a realidade do produto e a sua aparência na embalagem: a cor das ervilhas na ilustração contrasta com outros elementos decorativos do pacote, que são de um tom verde-neon quase gritante.

Como se não bastassem as ressalvas à forma como as ervilhas congeladas são apresentadas na embalagem, o missivista se sente ainda mais indignado quando a compara com a dos concorrentes, descobrindo a lógica mercadológica que promove a maquiagem dos produtos:

A maioria dos fabricantes de alimentos estampam produtos mais apetecíveis do que os que se encontram dentro do pacote, sendo portanto enganosos nessa representação. Os senhores fazem o contrário: estão falsamente representando suas ervilhas como menos saborosas do que elas são na realidade. (DAVIS, 2017, p. 46).

Com esse comentário, o missivista reforça a sua certeza de que a representação das ervilhas congeladas na referida embalagem "é extraordinariamente menos sedutora" do que a dos demais fabricantes e aqui, na posição de um zeloso gestor de imagem da marca da empresa, atento às opiniões de seu público, "pede" que o fabricante "reconsidere a identidade visual" de suas embalagens.

Curiosamente a identidade do autor dessa carta-sugestão-reivindicação não é revelada, mas, pela regência dos verbos mobilizados - decidimos, achamos, referimo-nos, comparamos etc. -, o narrador, em primeira pessoa do plural, representa uma voz coletiva, um contingente de consumidores, não apenas um indivíduo. Ele não assume a posição daquele consumidor que, nos moldes do passado, encaminhava uma carta à empresa ou telefonava para o Serviço de Atendimento ao Consumidor (SAC). Ele não é o exército de um homem só, mas o contrário: um homem só com poder de exército.

No contexto midiático contemporâneo, com a ação rizomática das redes sociais em suas mãos, o consumidor, como discute Domingues (2013) em Terrorismo de marca, tem se reunido em grupos não apenas para protestar, mas para boicotar marcas que desrespeitaram o público de forma constante ou pontual (em situações específicas). A 
internet se configura como uma arena na qual se travam lutas discursivas entre as marcas anunciantes e entre as marcas e seus consumidores, visto que nela se encontra

[...] uma série de vídeos, sites, blogs e comunidades virtuais alusivas a marcas, empresas e produtos divulgando aspectos diferentes daqueles apresentados pelos enunciados oficiais proferidos nas propagandas institucionais. Marcas globais [...] lidam, na atualidade, com discursos variados criados pelos consumidores, destacando atributos pouco lisonjeiros para essas marcas. (DOMINGUES, 2013, p. 58).

O advento do prossumidor - termo cunhado por Alvin Tofler em 1980, no livro $A$ terceira onda, ao definir o sujeito que é produtor e, ao mesmo tempo, consumidor - se estabelece e, com o avanço das mídias digitais, expande-se para a produção de bens simbólicos. 0 prossumidor monta o carro com as características que lhe agradam no site do fabricante (o caso do Fiat Mio é exemplar), faz sua própria página no Facebook, grava seus vídeos pelo celular e os posta no YouTube, e não apenas faz críticas a produtos nas redes digitais - como o missivista do conto de Lydia Davis (2017) -, mas produz manifestos, caricaturas, memes e contra-propaganda, atacando as corporações que maltratam animais ou demonstram atitudes racistas, falocêntricas, homofóbicas etc.

A malha dialógica, portanto, entre os discursos das empresas e os discursos dos consumidores ganha novas nuanças, que revelam maior complexidade (e não menos conflitos) na relação entre ambas as esferas. Assim, se antes poderíamos interpretar que o consumidor que envia a tal carta ao fabricante de ervilhas congeladas solicita a mudança na embalagem, hoje uma carta assim pode significar menos um pedido e mais um alerta, um sinal de disjunção entre esse e aquele, o que, em última instância, resultaria na suspensão do consumo. No fim da carta ao fabricante na ficção de Davis (2017), o missivista, no entanto, escreve: “[...] gostamos de suas ervilhas e não queremos que sua empresa tenha prejuízos”. (DAVIS, 2017, p. 46). Temos nesse trecho uma questão crucial sobre os limites do poder do consumidor: há um real interesse de sua parte no sucesso da marca e na excelência do produto que ela fabrica, ou tão somente uma nota de ironia?

Chevalier e Mazzalovo (2007) confirmam que a maioria das principais marcas mantém canais abertos para o contato com o cliente, com atenção aos seus comentários, que por vezes se tornam contribuições relevantes para atualizações e aperfeiçoamentos nos produtos. Mas “[...] é geralmente por meio de ações coletivas mais estruturadas que os consumidores realmente podem propor medidas às empresas [...]" (CHEVALIER E MAZZALOVO, 2007, p. 278) e, acrescentamos nós, ter mais chances de serem atendidos. 
Se, pela internet, qualquer indivíduo pode detratar uma marca, atacando-a com ou sem razão, como Domingues (2013) examina nos casos da Nike, da Coca-Cola, da FKC, do Burger King e da Disney, é comum também encontrarmos discursos laudatórios de "fiéis" consumidores de marcas, com elogios à qualidade de suas mercadorias, às suas ações promocionais e às suas campanhas publicitárias.

A tensão entre a propaganda das corporações e a contra-propaganda de grupos sociais (consumidores ou não de seus produtos) sobe ao palco da mídia de massa, sendo levada a extremos, como a ideia das lovermarks de um lado - as marcas que atingem a condição de serem "amadas" (ROBERTS, 2004) - e, de outro, as Organizações NãoGovernamentais (ONGs) ou publicações ativistas, como a revista canadense Adbuster, que se posicionam contrárias ao consumo. Aí o mais correto seria dizer contrárias ao consumismo - palavra que designa o consumo sem freios, mas que também é problemática, uma vez que não há um medidor para os limites do consumo.

Da mesma forma que se estabelece essa dicotomia discursiva entre a comunicação dos fabricantes e a dos consumidores, há duas vertentes interpretativas do termo prossumo. Em sua obra Cultura do consumo, Fontenelle (2017) nos lembra que, se é visto como uma forma de empoderamento do consumidor, o prossumo, na via oposta, é considerado uma maneira inédita de alienação e exploração do trabalho através do consumidor. A questão segue aberta - sobretudo com campanhas como a da cerveja Skol que, em 2017, convidou mulheres para refazerem seus materiais publicitários em que havia mensagens machistas SACCHITIELLO, 2017) - e excede as divisas desta reflexão.

\section{Da embalagem para a anunciação sistemática}

Outra questão relativa à representação dos produtos em suas embalagens, em especial os alimentícios (mas não só), é a maneira como são retratados nas peças publicitárias que os promovem.

Carrascoza (2015) afirma que a narrativa publicitária mimetiza a narrativa ficcional de cunho realista, a qual visa, como a sua matriz literária, a criar efeitos de sentido do real por meio da verossimilhança. Pois bem: para mostrar ao consumidor a excelência do produto (a sua materialidade) e atraí-lo por meio de appetite appeal, um cuidadoso investimento imagético é conduzido pela publicidade, a fim de criar o efeito de realidade, que, em última instância, é uma regra do jogo seguida por seus criadores e presumida, ainda que não em detalhes, pelo público. Em outras palavras, o consumidor reconhece e 
aceita a perfeição do produto nas imagens publicitárias, sabendo, contudo, que não correspondem às suas condições físicas evidentemente imperfeitas.

Não por acaso Rocha (1990) acentua o caráter "mágico-totêmico", refratário à transformação, do sistema publicitário, bem como o seu movimento de supressão do tempo, o seu esforço para "esconder a mudança e eleger a permanência". Tanto na representação de um alimento - as ervilhas, por exemplo - numa embalagem, quanto em sua aparição publicitária num prato finalizado por um chef e pronto para ser servido, a passagem do tempo está sob o efeito de freios, e o produto está (e continuará) em sua plenitude de sabor, investido do poder de despertar no consumidor (que já o consome simbolicamente) o desejo de experimentá-lo.

Em harmonia com o campo semântico da esfera cosmética (make-up), chama-se no universo da publicidade de mock-up a réplica, a fabricação falsa de um produto visando à sua esmerada reprodução em materiais publicitários (anúncios, vídeos, folhetos etc.). A comida cenográfica, como uma exigência da publicidade, apresenta-nos um produto visualmente impecável, já que o tempo nele não incide, está represado em sua materialidade fake.

Os mock-ups são essenciais para a narrativa ficcional que a publicidade dissemina na mídia e, uma vez que sua aparição se dá num anúncio, o público estará consumindo por meio dela uma representação perfeita do alimento, enquanto o imperfeito segue regendo o mundo fora da peça publicitária, deteriorando-o a ponto de ser sempre frustrante o resultado de seu registro fotográfico in natura, daí o estratagema de usar a maquiagem.

Não é comum comparar a imagem sublime de uma comida cenográfica (usada para, paradoxalmente, despertar appetite appeal e, ao mesmo tempo, não ser possível o consumo) e a imagem do alimento verdadeiro: a estética forjada pela produção fotográfica do sistema publicitário supera a do produto real, a um passo do consumo.

$\mathrm{Na}$ internet, no entanto, é possível encontrarmos exemplos dessa comparação. Abaixo, podemos notar a foto de uma porção de batatas fritas do McDonald's produzida pela publicidade e sua correspondente real (Figura 1): 
Figura 1 - Batatas fritas Mc Donald's - Quadro comparativo

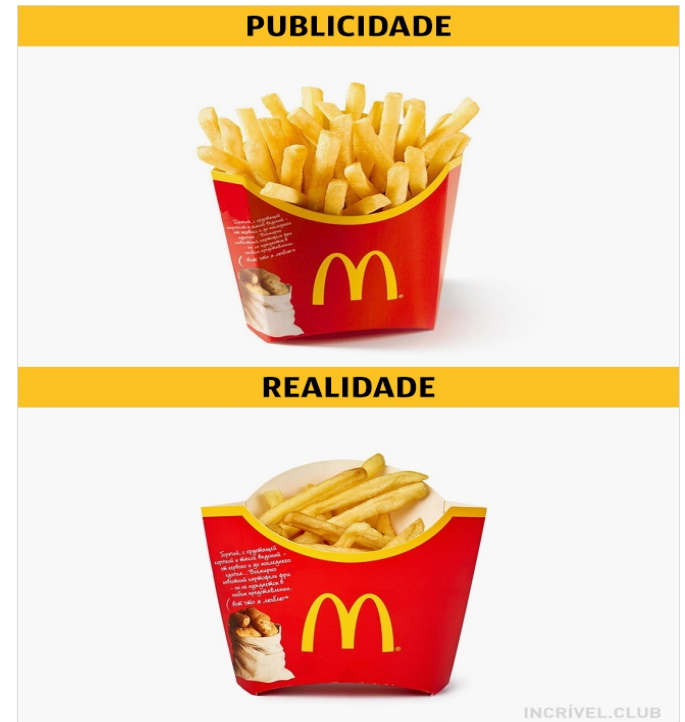

Fonte: Incrível.club

Outras marcas, que atuam no segmento de fast-food, agem da mesma maneira, como demonstram a foto cenográfica de um Crispy Chicken do Burger King e, em seguida, o sanduíche sem a cosmética publicitária (Figura 2):

Figura 2 - Crispy Chicken Burger King - Quadro comparativo

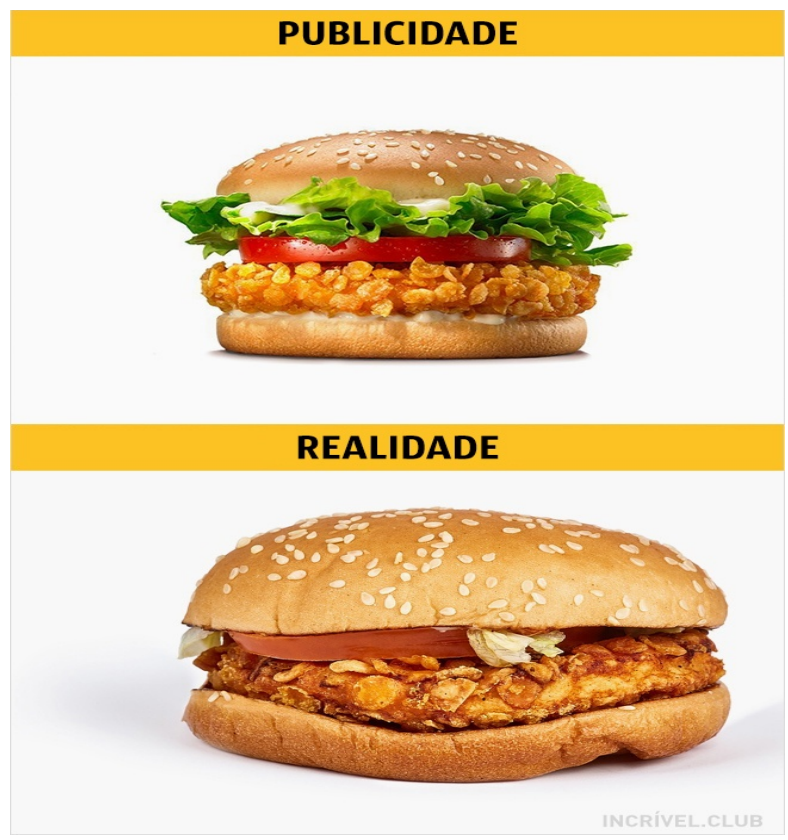

Fonte: Incrível.club 
Duas versões fotográficas (com mock-up e sem) de um Twister com queijo do KFC

(Figura 3) nos dão mais um exemplo:

Figura 3 - Twister com queijo KFC - Quadro comparativo

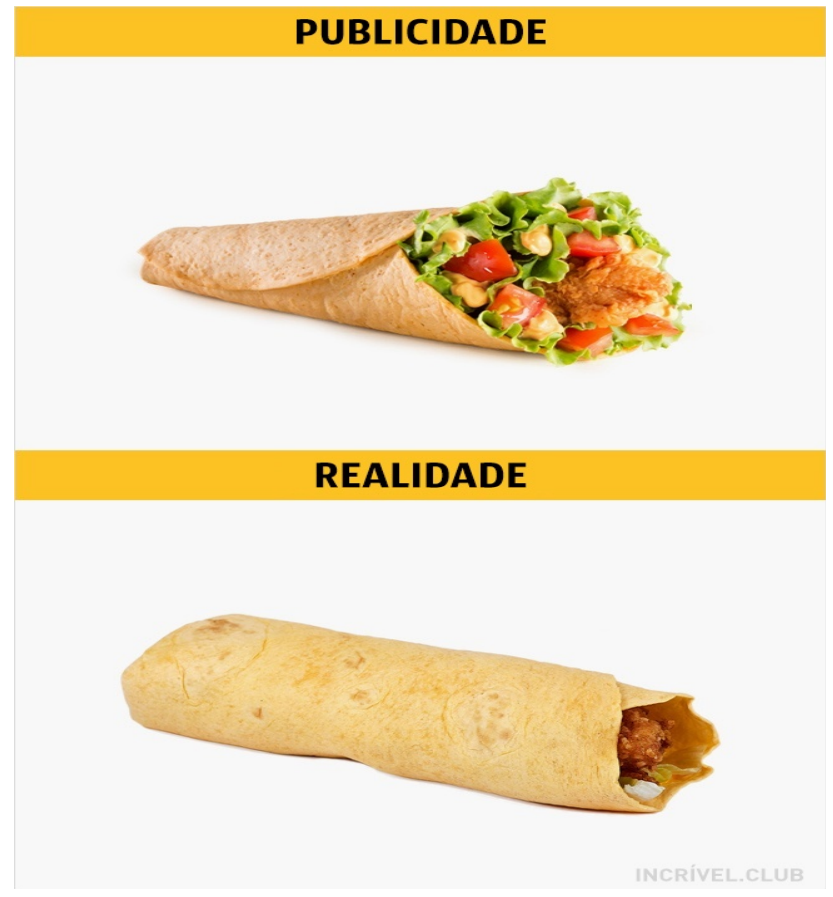

Fonte: Incrível.club

No entanto, o consumidor, mesmo ciente da diferença entre o que ele "vê" por meio do sistema publicitário e o que efetivamente come, continua aberto à sedução. Lipovetsky (2000, p.7) afirma que “[...] a publicidade não consegue fazer com que se deseje o indesejável [...]" (LIPOVETSKY, 2000, p. 7); ou seja, ninguém é capaz de seduzir quem não está predisposto a ser seduzido.

Indignado, o fotógrafo Oliviero Toscani (1995), que também "retoca" imagens, critica a cosmética da exuberância, com inúmeros exemplos, como este, a seguir:

Pela manhã, mamãe passa um creme miraculoso sobre o rosto com suas mãos suaves e embelezadas pelos produtos de limpeza, e aquelas unhas longas e pintadas que não se quebram nunca. As rugas somem como que por encanto, os lábios brilham e dobram-se como os que de uma atriz de cinema: a celulite desaparece sob os seus dedos, os seios tornam-se firmes e saltam na direção do céu azul [...] (TOSCANI, 1995, p. 15).

Mas o que se poderia esperar do sistema publicitário senão o impossível, em cuja possibilidade o consumidor continua a acreditar mesmo sabendo que não existe? 
O mundo real (das mudanças) em contraposição ao mundo ritual (da permanência) preconizado pela publicidade nos transporta ao romance $O$ retrato de Dorian Gray, de Oscar Wilde (2012), no qual o protagonista da história se mantém jovem, como quando foi retratado numa pintura (na qual o tempo, como numa embalagem, está congelado) e, na imagem ao contrário, a sua vida degenera sob a abrasão do tempo, efeito comum em todo ser humano.

No plano das embalagens mercadológicas e das peças publicitárias, o que se destaca é a aparência virtual, não a virtude do produto, pois a primeira é imutável e a segunda velozmente perecível. Ou, transpondo o ponto de vista de Rocha (1990) para esse aspecto, a comida real, vista pelos olhos do consumidor, nos mostra a sua imperfeição (humana), enquanto a comida cenográfica vista (ou revestida) pela "magia" de sua maquiagem nos apresenta a sua aura (divinal).

Em outras palavras, não convém à publicidade trazer Cronos, o tempo em seu continnum, para reproduzir a fiel imagem dos alimentos (em visível imperfeição), mas, sim, valer-se de Kairós, o tempo no momento oportuno, aquele em que todas as variáveis estão sob controle para que se registre o auge (até estético) da comida. 0 produto, não obstante a sua suprema perfeição, não pode revelar soberba, por isso é invariavelmente inserido na cena fotográfica na forma de um detalhe expressivo (CARRASCOZA, 2015), como no anúncio das salsichas Gasser (Figura 4).

Figura 4 - Anúncio das salsichas Gasser

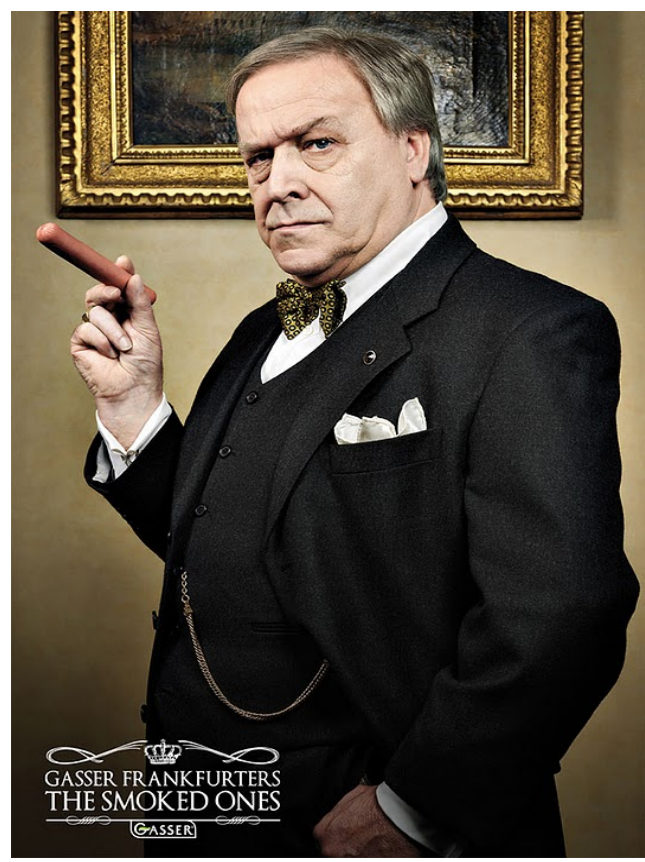

Fonte: Designer Daily 
O produto, como em toda lógica publicitária, é inserido na cena de um anúncio de forma a ocupar um pequeno espaço, muito embora só aparentemente ele seja um elemento secundário. 0 produto é o principal, mas, como nos lembra o poeta Fernando Pessoa (FERREIRA, 1986), que também se dedicou à publicidade e fez pequenas teorizações sobre a arte do comércio, “ [...] o princípio essencial da publicidade deve ser de esconder o máximo possível, ou de tornar o mais agradável possível, o intuito publicitário." (FERREIRA, 1986, p. 148).

Retomando o texto de Lydia Davis (2017), a crítica do missivista em sua carta ao fabricante de ervilhas aponta justamente para o descuido com o appetite appeal do produto, em relação a seus concorrentes - que seguem a cartilha da publicidade, zelando pela reprodução de sua comida cenográfica: “[...] comparamos sua representação de ervilhas com a de outros fabricantes e a sua é extraordinariamente menos sedutora." (DAVIS, 2017, p. 46).

\section{Em suma: ervilhas maquiadas}

A Carta a um fabricante de ervilhas congeladas nos mostra uma crítica à cor desse alimento em sua embalagem, pontuando que as ervilhas não parecem frescas, como de fato o são dentro dela - uma ironia do missivista, já que se são ervilhas congeladas, não podem ser, a rigor, ervilhas frescas. 0 consumidor reclama da qualidade de sua cópia cenográfica, que reduz seu efeito de sedução. Fica evidente que ele sabe da maquiagem feita pelo sistema publicitário - no qual a aparência dada ao produto é parte inicial de seu processo de promoção, que segue daí em diante, continuamente, com as campanhas de publicidade. Ele sabe, parafraseando os versos de Cecília Meireles (2001) no poema Retrato, que o produto não tem essa face que a publicidade lhe concede.

Aliás, relembremos, tanto a maquiagem nas embalagens dos alimentos quanto os alimentos fakes nas peças publicitárias já são uma forma de consumo - sígnico, discursivo, mediático. Uma forma de permanência da marca na vida do consumidor, sem a prerrogativa do consumo material do produto.

Ainda que as ressalvas do consumidor possam ser incorporadas pelos fabricantes e resultar em melhoramentos para suas mercadorias, não deixa de ser expressivo o espaço que esse consumidor encontra hoje nas redes sociais para fazê-lo, nem desprezível o fato de que, não raro, sua crítica (ou seu elogio) seja uma zombaria disfarçada, um antidiscurso subreptício.

Coincidentemente, em Mobília de família, conto da escritora canadense Alice Munro (2013) - Prêmio Nobel de Literatura -, um personagem, tio da protagonista da história, à 
mesa do almoço, tenta convencê-la de que as ervilhas (e cenouras) congeladas em seu prato são melhores não apenas que as enlatadas, mas até mesmo que as frescas (tanto na cor, quanto no sabor). Extraordinário, argumenta o homem, o que já se pode “[...] fazer hoje e o que seria feito com coisas congeladas no futuro." (MUNRO, 2013, p. 121). Certamente o make-up, feito pelo CC-P (complexo comercial-publicitário) na embalagem dos legumes, contribuiu para esquentar a opinião desse consumidor. A maquiagem é o rastilho para ação do fetiche e o fogo para as chamas do consumo.

\section{Referências}

BETTETINI, Gianfranco. La conversación audiovisual. Barcelona: Cátedra, 1996.

CARRASCOZA, João Anzanello. Estratégias criativas da publicidade. São Paulo: Saraiva, 2015.

CHEVALIER, Michel; MAZZALOVO, Gérald. Pró-logo. Marcas como fator de progresso. São Paulo: Panda Books, 2007.

DAVIS, Lydia. Nem vem. São Paulo: Companhia das Letras, 2017.

DESIGNER DAILY. Graphic \& Web design blog. [S. l.: s. n.], [2018]. Disponível em: https://www.designer-daily.com/18-cool-examples-of-food-advertising-50801. Acesso em: 07 set. 2018.

DOMINGUES, Izabela. Terrorismo de marca - Publicidade, discurso e consumerismo político na rede. Rio de Janeiro: Confraria do vento, 2013.

FERREIRA, António Mega (Org.). Fernando Pessoa. 0 comércio e a publicidade. Lisboa: Cinevoz/Lusomedia, 1986.

FONTENELLE, Isleide Arruda. Cultura do consumo - Fundamentos e formas contemporâneas. São Paulo: FGV Editora, 2017.

INCRÍVEL.CLUB. Fast food: publicidade vs realidade. [S. l.: s. n.], [2018]. Disponível em: https://incrivel.club/admiracao-fotografia/fast-food-publicidade-vs-realidade-70855/.

Acesso em: 18 set. 2018.

LIPOVETSKY, Gilles. Sedução, publicidade e pós-modernidade. Revista FAMECOS, Porto Alegre, n. 12, junho 2000.

MARX, Karl. Para a crítica da economia política. São Paulo: Abril Cultural, 1992.

MARX, Karl. 0 capital. Livro I. São Paulo: Boitempo, 2011.

MEIRELES, Cecília. Antologia poética. Rio de Janeiro: Nova Fronteira, 2001. 
MUNRO, Alice. Ódio, amizade, namoro, amor, casamento. 2a . ed. São Paulo: Editora Globo, 2013.

ROBERTS, Kevin. Lovemarks. 0 futuro além das marcas. São Paulo: M. Books, 2004.

ROCHA, Everardo. Magia e capitalismo - Um estudo antropológico da publicidade. $2^{\mathrm{a}}$. ed. São Paulo: Brasiliense, 1990.

SACCHITIELLO, Bárbara. Skol assume passado machista e ressalta a importância de evoluir. $[S . \quad$ l. $]$ : Meio \& Mensagem, 9 mar. 2017. Disponível em: http://www.meioemensagem.com.br/home/comunicacao/2017/03/09/skol-assumepassado-machista-e-ressalta-a-importancia-de-evoluir.html. Acesso em: 17 set. 2018.

SODRÉ, Eduardo. Site Fiat Mio reúne sugestões do público para fazer um carro. [S. l.]: 0 Globo, 24 jan. 2010. Disponível em: https://oglobo.globo.com/economia/site-fiat-mioreune-sugestoes-do-publico-para-fazer-um-carro-3064404. Acesso em: 18 set. 2018.

TOFLER, Alvin. A terceira onda. Rio de Janeiro: Record, 2014.

TORRES I PRAT, Joan. Consumo, luego existo - Poder, mercado y publicidad. Barcelona: Icaria, 2005.

TOSCANI, Oliviero. A publicidade é um cadáver que nos sorri. Rio de Janeiro: Ediouro, 1995.

WILDE, Oscar. 0 retrato de Dorian Gray. São Paulo: Penguin-Cia das Letras, 2012.

\title{
Frozen peas - the contemporary prosumer and the cosmetic exuberance of products
}

\begin{abstract}
With the consolidation of consumer culture during the past decades, new agents in the relation between production and consumption have appeared - among them the prosumer - a consumer who is a producer as well, since he participates, voluntarily or not, in the production process of goods. In this article, we intend to discuss aspects of the prosumer's "contribution" to the development of products as well as to virtual boycotts of their manufacturers, by means of the short story Letter to a frozen peas manufacturer, by the writer Lydia Davis (2017). In order to explore such aspects, we will mobilize concepts which are used in literary theory, in the description of the advertising creative process and in the studies on consumer society.
\end{abstract}

\section{Keywords}

Prosumer. Communication. Advertising. Packing. Literature. 
Recebido em 18/12/2018

Aceito em 22/08/2019 